\title{
MEASURING CONTROL DELAYS AT SIGNALIZED INTERSECTIONS IN MIXED TRAFFIC CONDITIONS
}

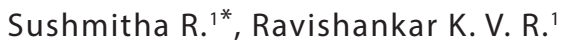

\begin{abstract}
Control delay is the key performance indicator of a signalized intersection that defines the level of service. Several models have been developed in previous research work for estimating control delays, but many of them were based on homogeneous traffic conditions. In the present study, an Open Street Map (OSM) tracker mobile application was used to measure control delays from the field. A non-linear model was developed in the present study for estimating control delays in mixed traffic conditions using a MATLAB fitting tool. The field delay is compared with the developed non-linear model delay along with the Indian Highway Capacity manual (INDO HCM) and Highway Capacity Manual (HCM) models. The control delay estimated using the model developed in the present study shows a close relation with the field delay obtained using an OSM tracker when compared to that obtained using the INDO HCM and HCM models. Therefore, the OSM tracker mobile application can be used as a field control delay measuring technique.
\end{abstract}

\author{
Address \\ 1 National Institute of Technology, Warangal, Telangana, India \\ * Corresponding author: susmitharamireddy@gmail.com
}

\section{Key words}

- OSM tracker,

- Non-linear model, Control delay,

- Mixed traffic.

\section{INTRODUCTION}

In India, the vehicle ownership rate is increasing rapidly due to the growth in the income levels of individuals. With the increase in the usage of private vehicles, there is a decrease in the use of public transportation, which results in severe congestion. The signalized intersections are the important nodes in the road network because of control delays that occur to the vehicles that are passing through intersections. Control delay is an important performance measure for interrupted flows such as those at signalised intersections. It is the sum of a deceleration delay, a stopped delay and a reacceleration delay. This is an important parameter that affects the capacity at an intersection. This paper focuses on measuring control delays in mixed traffic conditions. In previous research work, various measurement techniques were used to measure the field delays such as video photography by (Saha et al., 2017) in which they captured arrivals and departures to measure control delays. (Magfirona et al., 2015) measured control delays at signalized intersections in Indonesia using an area traffic control system (ACTS). (Quiroga et al., 1999) used GPS receivers to measure control delays at signalized intersections in Texas. (Arasan and Jagadeesh, 1995) measured control delays in the field using the Highway Capacity Manual 1985 procedure. The present study employed the Open Street Map (OSM) tracker mobile application to measure control delays in the field because it gives an accurate moment-to-moment position of the vehicles along with the deceleration and acceleration rates. By using this application, it is easy to extract the information compared to the video photography technique. (Jayakrishna and Ravishankar, 2019) used an OSM tracker to collect travel time data in a corridor. This mobile application provides information concerning the latitude, longitude, time intervals and speed. An OSM tracker is a free mobile application that can easily be downloaded from the Google Play Store. This mobile application is easy to use and does 
not require any special training for its operation. Once the application starts, data such as the longitude, latitude, speed and time intervals will be recorded and stored as a "GPX" file, which can be easily exported into Microsoft Excel. This mobile application requires the internet and GPS to be turned on when the survey is started. The accuracy of the OSM tracker is one second.

The present research aims to check the applicability of an OSM tracker mobile in measuring control delays in the field. A non-linear model was developed for the present research work using a MAT LAB fitting tool based on the following parameters: cycle time (seconds), volume ( $\mathrm{veh} / \mathrm{h}$ ), degree of saturation and percentage of easily manoeuvrable vehicles (two wheelers and three wheelers). The predicted control delay values are compared to those obtained from the field using an OSM tracker.

\section{LITERATURE REVIEW}

Different techniques are used to measure and estimate control delays around the world, but most of the models are based on homogeneous traffic conditions, and only a few studies have focused on measuring control delays in mixed traffic conditions. (Saha et al., 2017) proposed some modifications to the HCM delay model on the basis of traffic data collected from seven four-legged intersections. The inter-green time, number of phases, number of lanes and left turn on red at an intersection, volume/capacity ratio, green time/cycle time ratio, traffic volume, capacity, saturation flow, and platoon ratio are the factors considered for modelling delays at signalised intersections in the present study. The length of any queue was measured directly from the field observations and the delay was estimated based on the queue length of a cycle using Simpson's one-third rule. The proposed model was compared with popular models available for estimating delays and it results in an estimated error of only $3.9 \%$, which is far better than other models available to estimate delays.

(Alkaissi and Hussain, 2020) estimated the total delays at signalized intersections in Baghdad, Iraq, using GPS receivers. A travel time delay model was proposed, which was proved to estimate actual field control delay values accurately. (Susilawati et al., 2020) analysed delay distribution patterns from speed distance and speed time profiles obtained from GPS data. The study proposed an application to generate control delay data based on an algorithm which was developed using ArcGIS. (Wolfe and Lane, 2018) studied the impact of the radius of right-turning vehicles on delays to through vehicles. The results showed that as the radius of the curvature of the right-turning movement decreases, the speed of the right-turning vehicles decreases and the delay to the through vehicles increases.

(Murat et al., 2014) investigated the relation between delays, vehicles queuing and signal timing. The delay was calculated using Webster 1958, HCM 2000 and Akcelik's 1993 delay calculation methods. The multiple linear regression model developed is used as a reliable estimation model for vehicle delays at isolated signalised intersections. The adjusted value of the Multiple Linear Regression Analysis Based Delay Estimation (MuLReD) model was obtained as 0.95 ; the outcomes it obtained were closer to the field observation values. (Ravisekhar et al., 2013) proposed a methodology for the development, calibration and validation of a micro-simulation model for delays for a $2.9 \mathrm{Km}$-long stretch. The average error of the Verkehr In Stadten-SIMulationsmodel (VISSIM) model was $4.95 \%$, which was a good fit. The mitigation measures were proposed in that study to reduce fuel consumption in the corridor. (Prasannakumar and Dhinakaran, 2012) found site-specific Passenger Car Unit (PCU) values using an area-to-velocity ratio. The saturation flow rate was found directly from the field using site specific PCU values. The delays were estimated from the field using the HCM 2000 field delay procedure. The Level Of Service (LOS) was defined using a new criteria on developed for the signalised intersections of Indian cities. (Chen et al., 2011) analysed and evaluated HCM 2000 and the Japan Society of Traffic Engineering (JSTE) guidelines and they determined that both HCM and JSTE are overestimating the saturation flow for traffic conditions in Japan. A binary logistic regression model was developed to find delays. It was determined that queue length and green time had a significant relationship with the saturation flow rate. (Jameel, 2011) indicated that the results of his analysis were the same for a theoretical delay model and a computed delay model, when the $\mathrm{V} / \mathrm{C}$ is less than or equal to 1 and the trend is different at slightly higher values of the $\mathrm{V} / \mathrm{C}$ ratio. It was found that the HCM model using SIDRA (a lanebased congestion modelling tool) has a smaller difference from field measurements in delay values than an HCM model using Highway Capacity Software (HCS) and a SIDRA model in all the $\mathrm{V} / \mathrm{C}$ values. The results of the analysis showed that for field delay ranges up to $80 \mathrm{sec}$, the HCS tends to be equal to the estimated control delay, but for higher delay values, it is underestimated.

(MINH et al., 2009) developed a multiple linear regression equation for saturation flows and a proposed modified Webster 1958 delay model to estimate delays under heterogeneous traffic conditions. It was determined that the output of the study was close to the observed data and was better than the conventional Webster model, especially when the degree of saturation is close to 1. (Yuelong et al., 2009) developed a model for delays by analysing the characteristics of traffic queue headways, taking into account the heterogeneous nature of mixed traffic flows and the unavoidable interference from pedestrians and bicyclists. Two dominant factors that affect the delay time, i.e., the portion of buses and heavy vehicles in a queue and its interference with the front vehicle, were considered in the study. A simplified delay estimation model was proposed that considers vehicle types and positions in a queue. (Hoque and AsifImran, 2007) developed a multiple linear regression model for estimating delays at signalized intersections. In this study, the first and second terms of the Webster model are kept the same, and the third term is modified using regression analysis. (Gokdag et al., 2007) proposed an adaptive neuro-fuzzy inference system based on delay estimation models and tested it through simulation and observation values. It was observed that a neuro fuzzy technique can be successfully applied to the modelling of traffic systems. (Ahmed and Lebdeh, 2005) presented an analytical delay model to quantify delays at signalised intersections. The basic traffic flow parameters, signal parameters and link geometry were the inputs used for the development of the model. The testing of the models was done on a hypothetical system under various geometric, control and traffic conditions. The results of the analysis revealed that the delay induced by downstream traffic operations on the upstream side of an intersection is significant, which may change timing and achieve steadiness if downstream queues, traffic flow and signal control measures change. (Cheng et al., 2003) the modified Webster delay equation by keeping the first term the same and changing the second term. The modified Webster's optimal cycle length equation shows better results for high volume conditions. In addition to the 


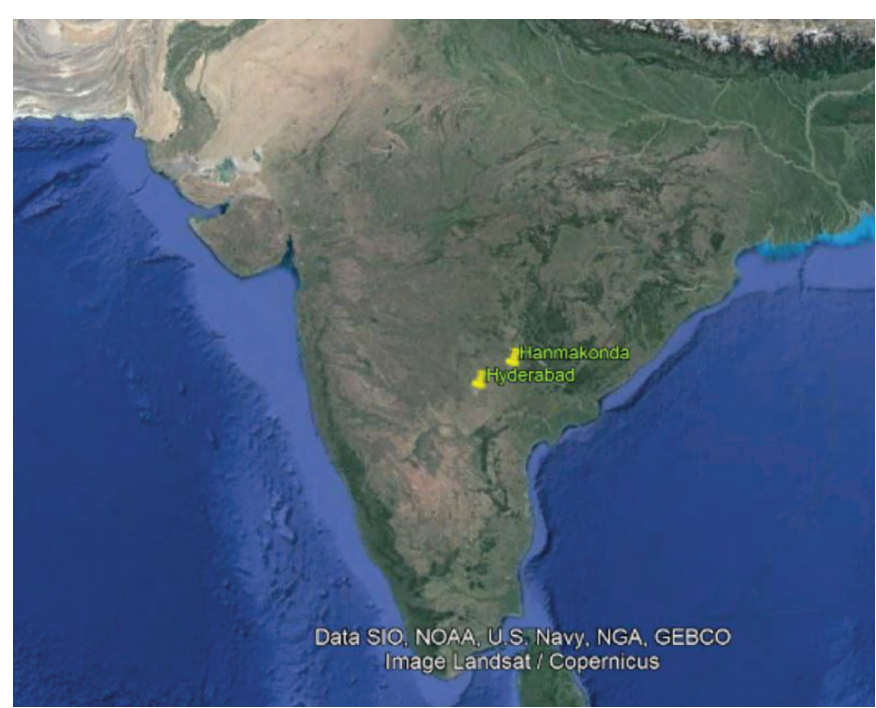

Fig. 1 Satellite map of the study area in the state of Telangana.

modified Webster's delay equation, an exponential cycle length model was developed that fits both high and low volume situations. Based on HCM 2000, they computed the minimum delay cycle lengths for a wide range of various traffic and lost time situations using the HCS software. (Mousa, 2002) conducted a study on the accuracy of the delays measured. The paper presented a methodology for measuring and analysing stop delays as well as acceleration and deceleration delays at a traffic signal. The results indicated that the deceleration and acceleration lengths of stopped vehicles varied over a wide range. The average acceleration-deceleration delay was estimated at $11.8 \mathrm{sec} / \mathrm{veh}$. The relationship between the delay components were modelled, and the analysis showed a ratio of 2 between the total delay and stopped delay.

(Quiroga et al., 1999) presented a new methodology for measuring delays at signalized intersections that uses GPS receivers and GIS dynamic segmentation tools. The main components of delays at a signalized intersection were determined by analysing the distance time, speed-time and acceleration time diagrams of a travel time run. (Bonneson, 1997) described a model for predicting delays on major streets from through vehicles due to right-turn activity. From the results of the sensitivity analysis using the model developed, it was determined that through vehicle delays due to rightturn activity range from 0.0 to $6.0 \mathrm{~s} / \mathrm{veh}$. The study showed that the average delay to through vehicles is small, but the total delay experienced by the through stream can be quite large. (Olszewski, 1993) proposed a stochastic delay model to estimate delays under various traffic conditions. It was observed that the shape of the probability distribution of delays under saturation conditions indicates a shifted exponential distribution, whereas in the case of fully saturated and over-saturated conditions, the shape of the distribution is flatter.

The majority of the studies using different models for estimating control delays using various field measurement techniques proposed a modified form of Webster's delay model and HCM models for estimating control delays. The majority of these delay studies are done under homogeneous traffic conditions. Only a few studies have been conducted under mixed traffic conditions

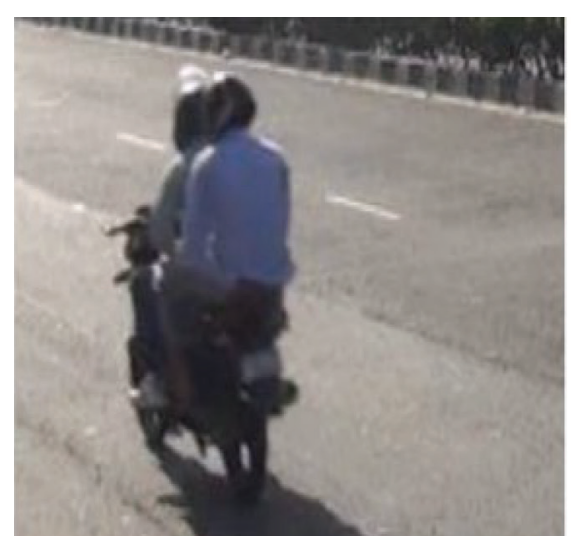

(a) $t w$

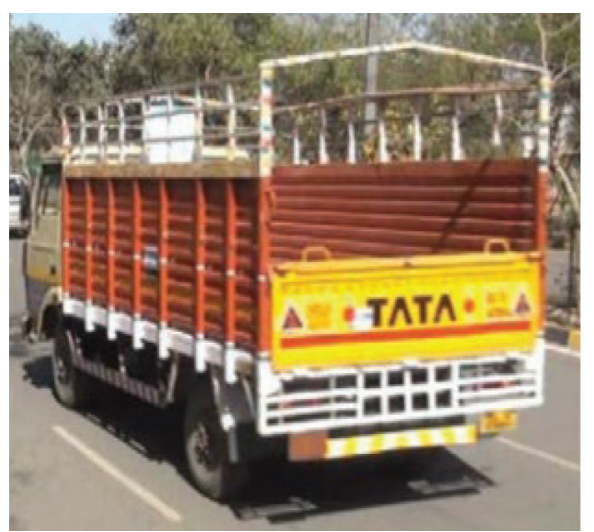

(d) $L C V$

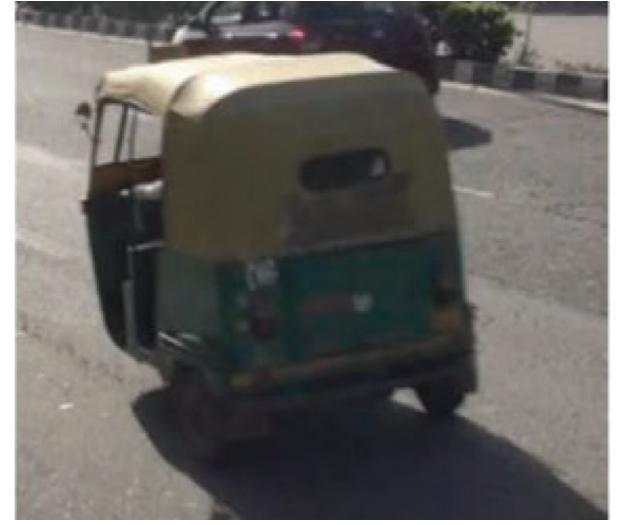

(b) $3 w$

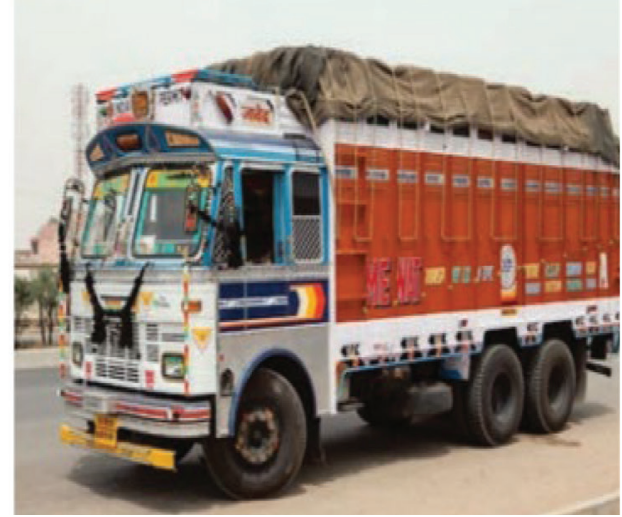

(e) $H V$

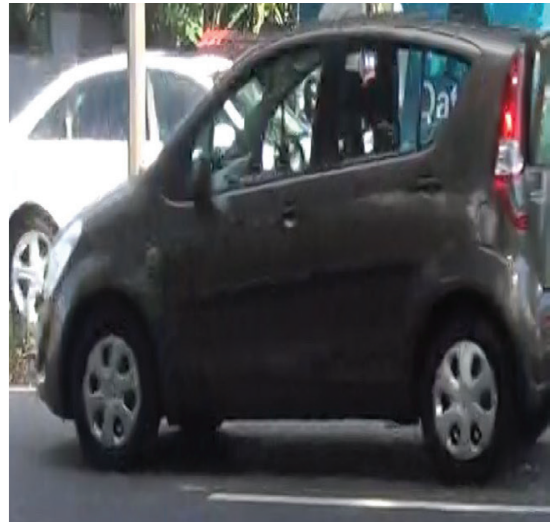

(c) Car

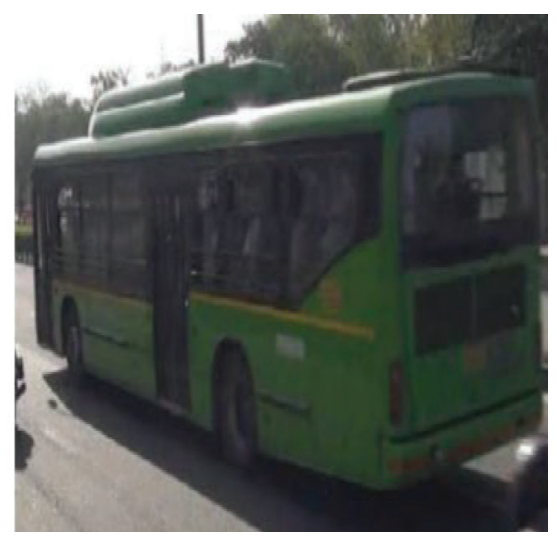

Fig.2 Vehicle categories. 
for estimating control delays. In the present study, an attempt is made to develop a non-linear model for control delays under mixed traffic conditions from the field data obtained using an OSM tracker mobile application.

\section{STUDY AREA}

For the present study six signalized intersections were selected from two different cities in the state of Telangana, i.e., Hanmakonda and Hyderabad. The KU and Kazipet intersections are in Hanmakonda. The Bachupally, Suchitra, Gandimaisamma and Patny circle intersections are in Hyderabad. All six intersections are four-legged intersections. Figure 1 shows a satellite map of the study area in Telangana state.

\section{DATA COLLECTION AND EXTRACTION}

The data collection included traffic data, geometric data and signal control characteristics. A video graphic method was used to collect traffic data from the field. Cameras were kept at an elevated position on top of an adjacent building so that the traffic manoeuvres from all the approaches were clearly visible. Geometric details such as the width of the approach and number of approaches were collected using a tape and odometer. Signal control characteristics such as the green time, amber time, red time, cycle time and number of phases were measured using a stop-watch. A classified vehicle volume count and turning movements were extracted every 15 minutes in order to identify the peak hours and saturated green intervals. The vehicles were categorized into five different categories: two wheeler (tw), three wheeler $(3 \mathrm{w})$, car (C), Light Commercial Vehicle (LCV), and Heavy Vehicle (HV). Images of the vehicle categories are shown in Figure 2.

A classified vehicle volume count and turning movements were collected every 5 seconds during saturated green intervals for measuring the saturation flow. The geometric and control details of the intersections selected are given in Table 1 .

The approaches of the intersections studied have approach widths varying from 5.5 meters to 10.5 meters and green times varying from 20 to 60 seconds. The degree of saturation $(\mathrm{X})$ is the ratio of the flow to the maximum possible flow under the given

Tab. 1 Geometric and control details of the selected intersections.

\begin{tabular}{|c|c|c|c|c|c|}
\hline Intersection & Approach & Approach width (m) & Green time (seconds) & $\begin{array}{c}\text { Amber time } \\
\text { (seconds) }\end{array}$ & Cycle time (seconds) \\
\hline \multirow{4}{*}{$\begin{array}{l}\mathrm{KU} \\
(\mathrm{I}-1)\end{array}$} & Karimnagar & 7 & 32 & \multirow{4}{*}{5} & \multirow{4}{*}{138} \\
\hline & Hanmakonda & 7 & 32 & & \\
\hline & $\begin{array}{c}100 \text { feet } \\
5.7\end{array}$ & & 27 & & \\
\hline & Bypass & 5.5 & 27 & & \\
\hline \multirow{4}{*}{$\begin{array}{c}\text { Kazipet } \\
\text { (I-2) }\end{array}$} & Hanmakonda & 8.6 & 35 & \multirow{4}{*}{4} & \multirow{4}{*}{136} \\
\hline & Hyderabad & 8.2 & 35 & & \\
\hline & Railway station & 6.2 & 30 & & \\
\hline & Vishnupuri & 6 & 20 & & \\
\hline \multirow{4}{*}{$\begin{array}{l}\text { Bachupally } \\
\text { (I-3) }\end{array}$} & Gandimaisamma & 7.5 & 45 & \multirow{4}{*}{3} & \multirow{4}{*}{162} \\
\hline & Nizampet & 5.3 & 30 & & \\
\hline & Mallampet & 6.4 & 45 & & \\
\hline & Miyapur & 7.3 & 30 & & \\
\hline \multirow{4}{*}{$\begin{array}{l}\text { Suchitra } \\
\text { (I-4) }\end{array}$} & Suchitra & 9.5 & 30 & \multirow{4}{*}{2} & \multirow{4}{*}{180} \\
\hline & Old Alwal & 10.5 & 30 & & \\
\hline & Bashirabad & 10 & 50 & & \\
\hline & Bowenpally & 10 & 60 & & \\
\hline \multirow{4}{*}{$\begin{array}{c}\text { Gandimaisamma } \\
\text { (I-5) }\end{array}$} & Balnagar & 7.5 & 45 & \multirow{4}{*}{3} & \multirow{4}{*}{147} \\
\hline & Temple & 5.5 & 30 & & \\
\hline & Miyapur & 5.5 & 35 & & \\
\hline & Narsapur & 5.8 & 25 & & \\
\hline \multirow{4}{*}{$\begin{array}{l}\text { Patny circle } \\
\text { (I-6) }\end{array}$} & Secunderabad & 6.8 & 25 & \multirow{4}{*}{3} & \multirow{4}{*}{100} \\
\hline & Begumpet & 7.9 & 25 & & \\
\hline & Paradise & 6.5 & 25 & & \\
\hline & Rastrapathi & 7.6 & 25 & & \\
\hline
\end{tabular}


conditions. The degree of saturation is calculated from the field data using the expression given in equation 1 :

$$
\mathrm{X}=\frac{q}{\lambda S}
$$

where, $\mathrm{X}=$ degree of saturation, $\mathrm{q}=$ volume in veh $\mathrm{h}, \boldsymbol{\lambda}=$ effective green ratio and $\mathrm{S}=$ saturation flow in veh/h.

The peak hour volume, degree of saturation and proportion of each vehicle category of the intersections studied were calculated from the field data and are given in Table 2.

Where, $\mathrm{P}-\mathrm{tw}=$ proportion of two wheelers, $\mathrm{P}-3 \mathrm{w}=$ Proportion of three wheelers, $\mathrm{P}-\mathrm{c}=$ Proportion of cars, $\mathrm{P}-\mathrm{LCV}=$ proportion of light commercial vehicles, $\mathrm{P}-\mathrm{HV}=$ Proportion of heavy vehicles. Under Indian traffic conditions, most of the traffic platoon con- sists of two wheelers, three wheelers and cars. Table 2 shows that the proportion of two wheelers is very high and varies from $37 \%$ to $56.6 \%$, but the proportion of heavy vehicles is much less and varies from $2 \%$ to $11 \%$.

\section{FIELD MEASUREMENT OF CONTROL DELAY}

The control delay data was collected from the field using an OSM tracker. The operation of the mobile application was started from the upstream side of the approach (before any deceleration starts) to the downstream side until the reacceleration is attained. Also, a video recording was done simultaneously for each run. As the OSM tracker gave the speed and corresponding time interval, the deceleration, stopped and acceleration delays could be accurately determined. A total of 40 runs was made for each intersec-

Tab. 2 Peak hour volume, Degree of saturation and proportion of vehicle categories.

\begin{tabular}{|c|c|c|c|c|c|c|c|c|}
\hline Intersection & Approach & Vol (veh/h) & Degree of saturation (X) & P-tw & P-3w & P-c & P-LCV & P-HV \\
\hline \multirow[t]{4}{*}{$\mathrm{I}-1$} & Karimnagar & 1050 & 0.63 & 0.41 & 0.12 & 0.34 & 0.07 & 0.06 \\
\hline & Hanmakonda & 1250 & 0.74 & 0.45 & 0.14 & 0.27 & 0.07 & 0.06 \\
\hline & 100 feet & 673 & 0.82 & 0.38 & 0.12 & 0.30 & 0.12 & 0.07 \\
\hline & Bypass & 893 & 0.47 & 0.39 & 0.13 & 0.26 & 0.13 & 0.08 \\
\hline \multirow[t]{4}{*}{$\mathrm{I}-2$} & Hanmakonda & 2450 & 0.81 & 0.40 & 0.16 & 0.33 & 0.05 & 0.05 \\
\hline & Hyderabad & 1898 & 0.65 & 0.37 & 0.12 & 0.35 & 0.09 & 0.06 \\
\hline & Railwaystation & 467 & 0.42 & 0.37 & 0.09 & 0.32 & 0.13 & 0.09 \\
\hline & Vishnupuri & 540 & 0.46 & 0.46 & 0.06 & 0.31 & 0.15 & 0.02 \\
\hline \multirow[t]{4}{*}{$\mathrm{I}-3$} & Gandimaisamma & 1326 & 0.85 & 0.52 & 0.17 & 0.20 & 0.05 & 0.05 \\
\hline & Nizampet & 669 & 0.66 & 0.44 & 0.09 & 0.26 & 0.12 & 0.07 \\
\hline & Mallampet & 950 & 0.76 & 0.49 & 0.14 & 0.27 & 0.09 & 0.02 \\
\hline & Miyapur & 1454 & 0.72 & 0.48 & 0.15 & 0.25 & 0.06 & 0.06 \\
\hline \multirow[t]{4}{*}{$\mathrm{I}-4$} & Suchitra & 1400 & 0.84 & 0.43 & 0.20 & 0.33 & 0.008 & 0.03 \\
\hline & Old alwal & 750 & 0.81 & 0.45 & 0.22 & 0.29 & 0.007 & 0.03 \\
\hline & Bashirabad & 3206 & 0.95 & 0.54 & 0.21 & 0.19 & 0.009 & 0.04 \\
\hline & Bowenpally & 3556 & 0.97 & 0.57 & 0.21 & 0.18 & 0.009 & 0.04 \\
\hline \multirow[t]{4}{*}{ I-5 } & Balnagar & 1860 & 0.72 & 0.44 & 0.17 & 0.30 & 0.04 & 0.03 \\
\hline & Temple & 850 & 0.54 & 0.42 & 0.08 & 0.25 & 0.15 & 0.11 \\
\hline & Miyapur & 1350 & 0.61 & 0.41 & 0.11 & 0.26 & 0.13 & 0.09 \\
\hline & Narsapur & 1960 & 0.83 & 0.48 & 0.17 & 0.18 & 0.11 & 0.05 \\
\hline \multirow[t]{4}{*}{ I-6 } & Secunderabad & 1009 & 0.60 & 0.44 & 0.18 & 0.32 & 0.03 & 0.02 \\
\hline & Begumpet & 1398 & 0.88 & 0.42 & 0.18 & 0.32 & 0.04 & 0.04 \\
\hline & Paradise & 986 & 0.51 & 0.40 & 0.13 & 0.31 & 0.08 & 0.06 \\
\hline & Rastrapathi & 1347 & 0.86 & 0.41 & 0.18 & 0.32 & 0.04 & 0.05 \\
\hline
\end{tabular}


tion with different categories of vehicles such as two-wheelers, three-wheelers, cars and LCVs. The average delay experienced by each category of the vehicle was calculated. Also, the average delay of all the vehicle categories passing through that approach was taken as the final average control delay (sec/veh) for that approach. Table 3 shows the field delays measured using the OSM tracker.

Tab. 3 Field delay measured using OSM tracker.

\begin{tabular}{|c|c|c|}
\hline Intersection & Approach & $\begin{array}{c}\text { Field average control } \\
\text { delay (seconds) }\end{array}$ \\
\hline \multirow{4}{*}{ I-1 } & Karimnagar & 116 \\
\hline & Hanmakonda & 126 \\
\hline & 100 feet & 112 \\
\hline & Bypass & 113 \\
\hline \multirow{4}{*}{$\mathrm{I}-2$} & Hanmakonda & 121 \\
\hline & Hyderabad & 110 \\
\hline & Railway station & 106 \\
\hline & Vishnupuri & 117 \\
\hline \multirow{4}{*}{ I-3 } & Gandimaisamma & 152 \\
\hline & Nizampet & 123 \\
\hline & Mallampet & 128 \\
\hline & Miyapur & 137 \\
\hline \multirow{4}{*}{$\mathrm{I}-4$} & Suchitra & 143 \\
\hline & Old Alwal & 138 \\
\hline & Bashirabad & 153 \\
\hline & Bowenpally & 163 \\
\hline \multirow{4}{*}{$\mathrm{I}-5$} & Balnagar & 126 \\
\hline & Temple & 114 \\
\hline & Miyapur & 116 \\
\hline & Narsapur & 145 \\
\hline \multirow{4}{*}{$\mathrm{I}-6$} & Secunderabad & 89 \\
\hline & Begumpet & 105 \\
\hline & Paradise & 87 \\
\hline & Rastrapathi & 108 \\
\hline
\end{tabular}

Table 3 shows the control delay is the summation of the deceleration, stopped and acceleration delays. The maximum and minimum values of the control delays were observed to be 163 seconds and 87 seconds respectively. The deceleration, stopped and acceleration delays were calculated from the field observations for each category of vehicle separately and are shown in the time-space diagram for the KU, Kazipet, Bachupally, Suchitra, Gandimaisamma and Patny circle intersections in Figures 3 to 8 respectively.

Figures 3 to 8 show control delay variations for two wheelers $(2 \mathrm{~W})$, three wheelers $(3 \mathrm{~W})$, car and LCVs (light commercial vehicle). It can be concluded that the deceleration and acceleration delays vary from vehicle to vehicle, whereas a stopped delay is almost the same for all of the vehicle categories. There were many variations in acceleration delays from one vehicle category

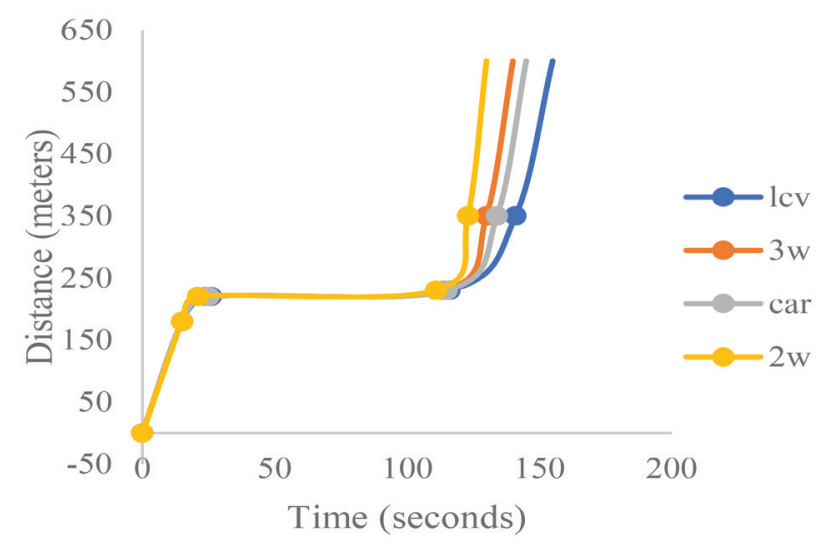

Fig. 3 Control delay for different vehicle categories at I-1.

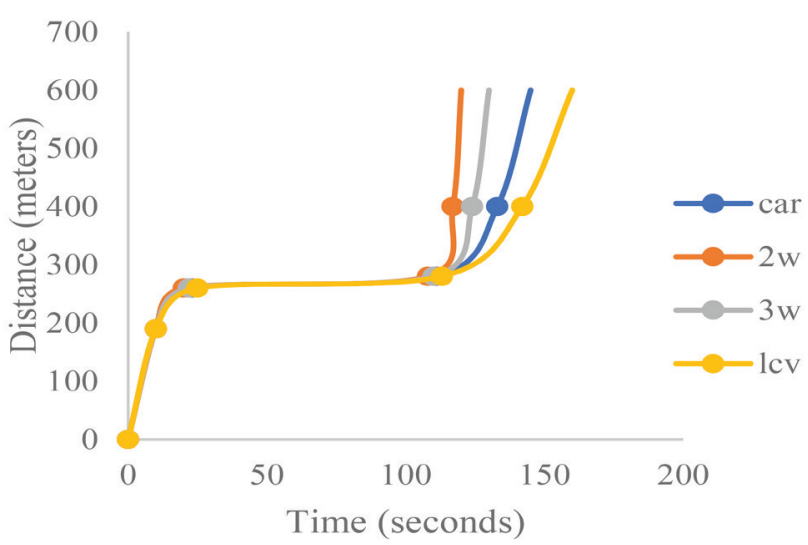

Fig. 4 Control delay for different vehicle categories at I-2.

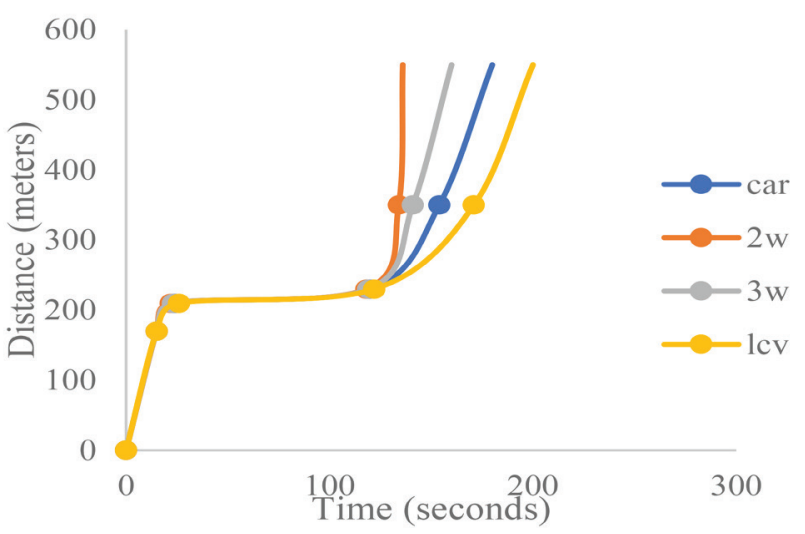

Fig. 5 Control delay for different vehicle categories at I-3.

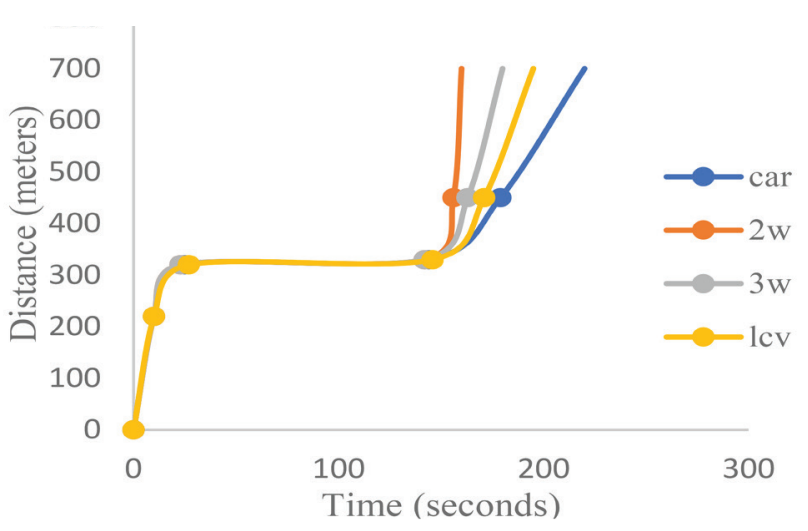

Fig. 6 Control delay for different vehicle categories at I-4. 


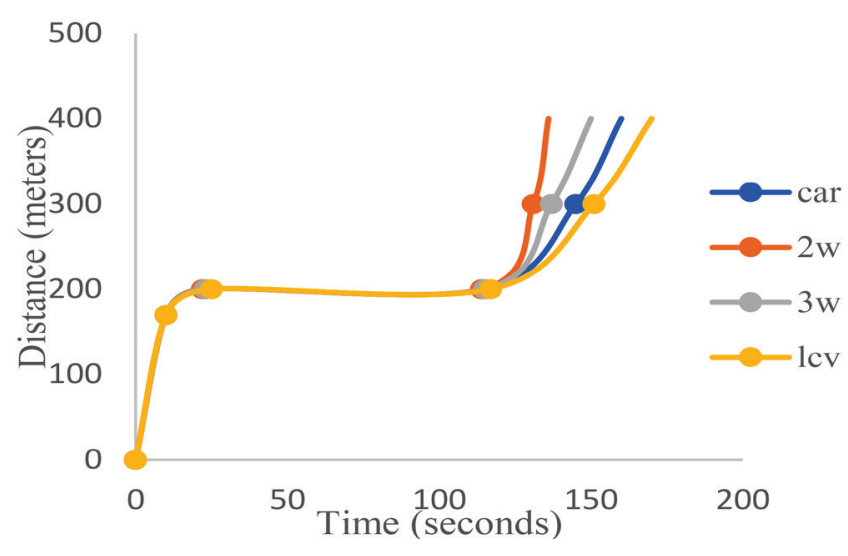

Fig. 7 Control delay for different vehicle categories at I-5.

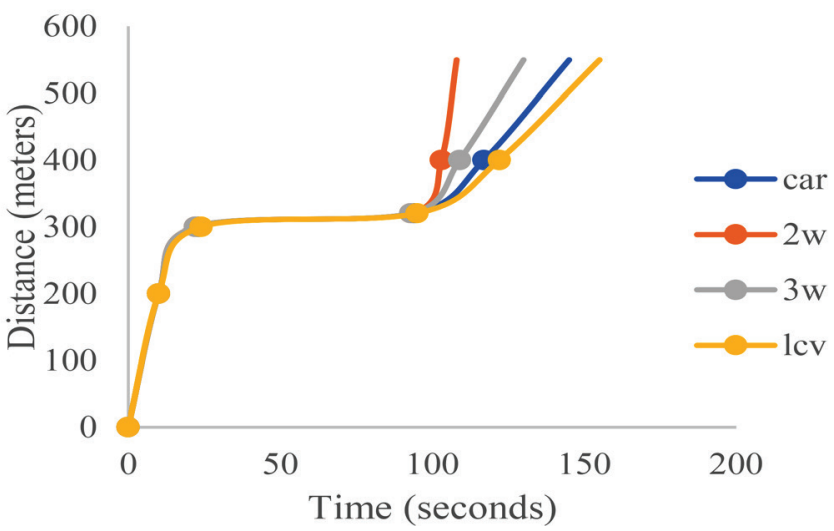

Fig. 8 Control delay for different vehicle categories at I-6.

to another vehicle category: the acceleration delay experienced by a two-wheeler is much less and it is high for an LCV. These variations are due to the presence of different vehicles in traffic with different acceleration capabilities.

\section{MODELLING THE CONTROL DELAYS}

The present study deals with the cycle time $(\mathrm{C}), \mathrm{G} / \mathrm{C}$ ratio $(\lambda)$, degree of saturation (X), peak hour volume (q) and proportion of easily manoeuvrable vehicles (two wheelers and three wheelers). However, a significant correlation of the control delays was observed with the cycle time, peak hour volume, degree of saturation and proportion of easily manoeuvrable vehicles. The correlation matrix of the significant variables is shown in Table 4.

Tab.4 Correlation matrix showing significant variables.

\begin{tabular}{llllll}
\hline & $\mathbf{D}$ & $\mathbf{C}$ & $\mathbf{q}$ & $\mathbf{X}$ & $\mathbf{P}$ \\
\hline $\mathbf{D}$ & 1 & & & & \\
\hline $\mathbf{C}$ & 0.977 & 1 & & & \\
\hline $\mathbf{Q}$ & 0.511 & 0.271 & 1 & & \\
\hline $\mathbf{X}$ & 0.975 & 0.449 & 0.354 & 1 & \\
\hline $\mathbf{P}$ & 0.737 & 0.361 & 0.271 & 0.210 & 1 \\
\hline
\end{tabular}

where, $\mathrm{D}=$ control delay in sec/veh, $\mathrm{C}=$ cycle time in seconds, $\mathrm{q}=$ peak hour volume in $\mathrm{veh} / \mathrm{h}, \mathrm{X}=$ degree of saturation, and $\mathrm{P}=$ proportion of easily manoeuvrable vehicles $(\mathrm{tw}+3 \mathrm{w})$.

In the present study, an attempt was made to fit the correlation between the variables using the MATLAB fitting tool. Compared to a linear model, a non-linear model gives an accurate estimation of control delays and is found to be significant with field results. Out of the six intersections studied four used the model calibration: I-1, I-2, I-4 and I-5. Equation 2 represents the model form obtained for estimating the control delays:

$$
d=(0.56 \times C)+(0.002 \times q)+\left(21.8 \times e^{X}\right)+(9.54 \times \ln (P))
$$

The R2 value of the model is 0.945. According to Equation 2, the cycle time and peak hour volume increase linearly with increases in control delays. Whereas, the degree of saturation exponentially increases, and the proportion of easily manoeuvrable vehicles logarithmically increases with increases in the control delays. Equation 2 is valid when the cycle time varies from 100 to $180 \mathrm{sec}$, the volume of an approach varies from 460 to $3556 \mathrm{veh} / \mathrm{h}$, the degree of saturation varies from 0.8 to 1.1 and the proportion of easily manoeuvrable vehicles varies from 0.46 to 0.78 .

Tab. 5 Comparison of control delay.

\begin{tabular}{|c|c|c|c|c|c|}
\hline Intersection & Approach & $\begin{array}{c}\text { Field control } \\
\text { delay ( } \mathrm{sec} / \mathrm{veh})\end{array}$ & $\begin{array}{c}\text { Control delay using non-linear } \\
\text { model (sec/veh) }\end{array}$ & $\begin{array}{c}\text { Control delay using INDO } \\
\text { HCM (2017) (sec/veh) }\end{array}$ & $\begin{array}{c}\text { Control delay using } \\
\text { HCM (2010) (sec/veh) }\end{array}$ \\
\hline \multirow{4}{*}{ I-1 } & Karimnagar & 116 & 125 & 132 & 176 \\
\hline & Hanmakonda & 126 & 131 & 135 & 183 \\
\hline & 100 feet & 112 & 122 & 129 & 162 \\
\hline & Bypass & 113 & 118 & 138 & 168 \\
\hline \multirow{4}{*}{$\mathrm{I}-2$} & Hanmakonda & 121 & 130 & 156 & 179 \\
\hline & Hyderabad & 110 & 119 & 119 & 158 \\
\hline & Railway station & 106 & 113 & 121 & 147 \\
\hline & Vishnupuri & 117 & 116 & 133 & 174 \\
\hline \multirow{4}{*}{$\mathrm{I}-4$} & Suchitra & 143 & 151 & 162 & 238 \\
\hline & Old alwal & 138 & 147 & 152 & 221 \\
\hline & Bashirabad & 153 & 164 & 179 & 245 \\
\hline & Bowenpally & 163 & 169 & 168 & 261 \\
\hline \multirow{4}{*}{$\mathrm{I}-5$} & Balnagar & 126 & 135 & 147 & 194 \\
\hline & Temple & 114 & 126 & 132 & 168 \\
\hline & Miyapur & 116 & 121 & 131 & 181 \\
\hline & Narsapur & 145 & 142 & 158 & 207 \\
\hline
\end{tabular}




\section{ESTIMATION OF CONTROL DELAY}

The Indian Highway Capacity manual (INDO HCM (2017)) was recently developed with the objective of illustrating the nationwide characteristics of road traffic and determining the capacity and level of service for mixed traffic for various urban and interurban roads, considering the various highway facilities such as blocks mid, un-signalized intersections, signalized intersections, and roundabouts. In this section, control delays are calculated using the non-linear model developed in the present study, INDO HCM (2017), and the HCM (2010) delay models. A brief comparison of the delay values is made with different models and presented in Table 5.

The control delays estimated by the different models was compared with the field control delay values. The delay values were estimated using the developed non-linear model, the INDO HCM (2017) model and the HCM (2010) model. The results obtained from the models are tabulated in Table 5. It was determined that the values obtained from the HCM (2010) model were very high compared to the field values because this model is widely applicable for homogeneous conditions. It therefore provides poor results for heterogeneous traffic conditions because it does not capture actual field conditions, especially in mixed traffic conditions. The INDO HCM (2017) model gives better results compared to the HCM (2010) model, but this is also not significant with the field values. As this method did not consider the actual deceleration and acceleration rates from the field and also used a single acceleration/deceleration correction factor irrespective of the speed range, the results are not close to the field values. The new model proposed in this paper to estimate delays considers different factors under mixed traffic conditions and is closer to field delay values under varying traffic conditions, which is significant.

\section{VALIDATION}

Validation is an essential step to represent the degree to which the developed model corresponds to a real system. Out of the six intersections studied, two were used for validation, i.e., I-3 and I-6. The validation of the two intersections, which was performed and observed versus the predicted control delays, is shown in Figure 9.

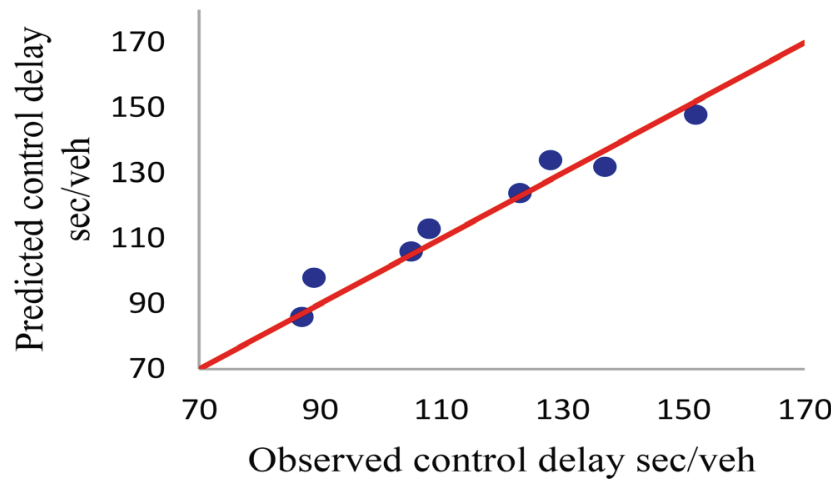

Fig. 9 Validation.

The predicted values shown a good degree of validation with the observed control delay values. The $\mathrm{P}$ value calculated from the Chi-square test at a $5 \%$ significance level is 0.67 , which is higher than 0.05 ; it therefore shows a good prediction of control delays. The accuracy and error measurements were calculated for all three estimated models versus the non-linear model developed in the present study, INDO HCM (2017) and HCM (2010). The relative percentage error (RPE), mean absolute percentage error (MAPE), and index of agreement (IA) were calculated for the control delay estimations and are represented in Equation 3, 4, and 5 respectively.

$$
\begin{gathered}
R P E=\frac{\left(y_{\exp }-y_{\text {pred }}\right)}{y_{\exp }} \times 100 \\
M A P E=\frac{1}{N}\left|\frac{y_{\exp }-y_{\text {pred }}}{y_{\exp }}\right| \\
I A=1-\left[\frac{\sum_{i=1}^{n}\left(y_{\text {pred }}-y_{\text {exp }}\right)^{2}}{\sum_{i=1}^{n}\left(\left|y_{\exp }-\overline{y_{\exp }}\right|+\left|y_{\text {pred }}-\overline{y_{\text {pred }}}\right|\right)^{2}}\right]
\end{gathered}
$$

where, $\mathrm{N}=$ number of observations, $\mathrm{y}_{\exp }=$ field control delay in sec/veh, $\mathrm{y}_{\text {pred }}=$ control delay in sec/veh estimated using the model developed, the INDO HCM (2017) model and the HCM (2010) model. Table 6 shows the accuracy and error calculations for the control delay estimations done by various methods.

Tab. 6 Accuracy and error measures.

\begin{tabular}{cccc}
\hline $\begin{array}{c}\text { Error and Accuracy } \\
\text { measurements }\end{array}$ & $\begin{array}{c}\text { Non-linear } \\
\text { model }\end{array}$ & $\begin{array}{c}\text { INDO HCM } \\
\text { (2017) model }\end{array}$ & $\begin{array}{c}\text { HCM } \\
(2010) \text { model }\end{array}$ \\
\hline \multirow{2}{*}{ RPE } & $\begin{array}{c}\text { Minimum } \\
0.65 \%\end{array}$ & $\begin{array}{c}\text { Minimum } \\
13 \%\end{array}$ & $\begin{array}{c}\text { Minimum } \\
37 \%\end{array}$ \\
\cline { 2 - 4 } & $\begin{array}{c}\text { Maximum } \\
10 \%\end{array}$ & $\begin{array}{c}\text { Maximum } \\
29 \%\end{array}$ & $\begin{array}{c}\text { Maximum } \\
73 \%\end{array}$ \\
\hline MAPE & $6.4 \%$ & $17 \%$ & $48 \%$ \\
\hline IA & 0.96 & 0.72 & 0.39 \\
\hline
\end{tabular}

Table 6 shows the errors and accuracy of the model developed are in an acceptable range, compared to those calculated using the INDO HCM (2017) and HCM (2010).

\section{CONCLUSIONS}

In this research work, the control delays at signalized intersections were analysed using an On Street Map (OSM) tracker mobile application. For this study six intersections from two different cities, i.e., Hyderabad and Hanmakonda, were considered. From the correlation analysis, the cycle time, peak hour volume, degree of saturation and proportion of easily manoeuvrable vehicles have been identified as variables influencing control delays. The INDO HCM (2017) and HCM (2010) models were used to estimate the control delay values for heterogeneous and homogeneous traffic conditions. Both of these methods are not sufficient to give delay values that are close enough to field values. The HCM (2010) model overestimates the delay values, as this model cannot account for heterogeneous traffic conditions, which have considerable significance in the estimation of delay values. Traffic conditions in countries such as India, where non-lane discipline exists, is different from that of homogeneous traffic conditions. Also, the HCM (2010) does not consider land use characteristics. 
The HCM (2010) model cannot therefore be applicable to Indian traffic conditions.

On the other hand, the INDO HCM (2017) manual, which was developed for heterogeneous traffic conditions, also does not provide close values but gives better predictions compared to the HCM (2010), but its main drawback is that it considers a single correction factor for acceleration/deceleration rates for all speed ranges at any time instead of actual acceleration/ deceleration rates. Due to this single correction factor, the estimate values are not close enough. INDO HCM (2017) defines a common control delay estimation model irrespective of city size, traffic and land use characteristics. The intersection characteristics vary as there are no provisions for exclusive bus bays, right-turning lanes, and parking facilities. The non-linear model developed estimates control delays close to the observed field saturation flows. This study helps estimating control delays in developing countries such as India, where mixed traffic with non-lane behaviour exists. It arrives at the design principles in signal phasing for the prevailing traffic conditions. It also can be used as an input for the simulation and analyse the effect of various factors and variations. In the present study, an OSM tracker was used to collect the field value delays. From the observations it has been concluded that the OSM tracker mobile application can be used as a control measure technique as it measures control delays accurately. This application gives variations of deceleration/ deceleration rates, which in turn give the best predictions of control delay values. This exact prediction of control delays helps in signal design.

This study has some limitations by which the number of intersections can be increased to clearly analyse the field control delays under various traffic proportions. Also, the OSM tracker mobile applications need an internet connection for their operation, which is difficult to operate in remote areas.

\section{Acknowledgements}

The authors would like to acknowledge the research assistance provided by the Ministry of Human Resources and Development, the Government of India. 


\section{REFERENCES}

Ahmed, K. - Ledbeh, H.A. (2005), Modeling of Delay Induced by Downstream Traffic Disturbances at Signalized Intersections. Journal of the Transportation Research Board, 1920(1), 106-117.

Alkaissi, Z.A.- Hussain, R.Y. (2020), Delay time analysis and modelling of signalized intersections using Global Positioning System (GPS) receivers. IOP conference series: Materials Science and Engineering. 3rd international conference on Engineering Sciences, 671, 1-15.

Arasan, V.T. - Jagadeesh, K. (1995), Effect of heterogeneity of traffic on delay at signalized intersections. Journal of Transportation Engineering, ASCE, 125(5), 397-404.

Bonneson, J, A. (1977) Delay to major-street through vehicles due to right turn activity. Transport Research, 32(2), 139-148.

Chen, P. - Nakamura, H. - Asano, M. (2011), Saturation flow rate analysis for shared left turn lane at signalized intersections in Japan. In: 6th International Symposium on Highway Capacity and Quality of Service, Stockholm, Sweden, June 28 - July 12011. Procedia Social and Behavioural sciences.

Cheng, D.X. - Messer, C.J. - Tian, Z.Z. - Liu, J. (2003), Modification of Webster's minimum delay cycle length equation based on HCM 2000. TRB 2003 annual meeting.

Gokdag, M. - Hasiloglu, A.S. - Karsli, N. - Atalay, A. - Akbas, A. (2007), Modeling of vehicle delays at signalized intersection with an adaptive neuro-fuzzy (ANFIS). Journal of Scientific \& Industrial Research, 66,736-740.

Highway Capacity Manual HCM (2010), TRB, Washington D.C, USA.

Hoque, S. Md. - Imran, A. Md. (2007), Modification of Webster's delay formula under non-lane based heterogeneous road traffic condition. Journal of Civil Engineering (IEB), 35(2), 81-92.

Indo HCM (2017), Indian Highway Capacity Manual, Council of Scientific and Industrial Research (CSIR), New Delhi, in 2017.

Jayakrishna, J. - Ravishankar, K.V.R. (2019), An innovative method of travel time data collection using mobile GPS application. International Journal of Transportation Engineering and Traffic Systems, 5(1), 42-50.

Jameel, A.K. (2011), Estimating delay time at Palestine street intersections in Bagadad city using HCM and SIDRA models. Al-Qadisiya Journal for Engineering and Sciences, 4(1), 613-633.

Kumar, R.P. - Dhinakaran, G. (2012), Estimation of delay at signalized intersections for mixed traffic conditions of a developing country. International Journal of Civil Engineering, 11(1), 53-59.
Magfirona, A. - Hidayati, N. - Setiyaningsih, I. - Slamet, G. (2015), The delays for signalized intersections using ACTS data and field survey method at Kerten intersection of Surakarta. Proceedia Engineering, 125, 526-533.

Minh, C.C. - Hoai, B. - Mai, T.T. - Sano, K. (2009), The delay estimation under heterogeneous Traffic conditions. Journal of the Eastern Asia Society for Transportation Studies, vol. 7, 1583-1595.

Mousa, R.M. (2002), “Analysis and Modeling of Measured Delays at Isolated Signalized Intersections." Journal of Transportation Engineering ASCE. DOI: 10.1061/ASCE0733-947X (2002), 128 (4).

Murat, Y.S. - Kutluhan, S. - Cakici, Z. (2014), Investigation of Cyclic Vehicle Queue and Delay Relationship for Isolated Signalized Intersections. EWGT2013 - 16th Meeting of the EURO Working Group on Transportation. Procedia - Social and Behavioural Sciences, $111,252-261$.

Olszewski, P. (1993), Overall delay, stopped delay and stops at signalized Intersections. Journal of Transportation Engineering, ASCE, 119 (6).

Quiroga, C.A. - Bullock, D. (1999), Measuring control delay at signalized intersections. Journal of Transportation Engineering, ASCE, 125 (4), 271-280.

Ravisekhar, Ch. - Raj, P. - Parida, P. - Gangopadhyay, S. (2013), Estimation of delay and fuel loss during idling of vehicles at signalized intersection in Ahmadabad. In: 2nd conference of Transport Research Group of India. Procedia- social and behavioural sciences, 104, 1178-1187.

Saha, A. - Chandra, S. - Ghosh, I. (2017), Delay at signalized Intersections under mixed traffic conditions. Journal of Transportation Engineering, ASCE, 143 (8).

Susilawati - Ramli, M. I- Yatmar, H. (2020), Delay distribution estimation at a signalized intersection. IOP conference series: Earth and Environmental Sciences, 419, 1-11.

Wolfe, F.A. - Lane, W. (2018), Effect of Radius of Curvature for Right Turning Vehicles on Through Traffic Delay. Transportation Research Circular E-C018: 4th International Symposium on Highway Capacity. 388-396.

Yuelong, SU. - Zheng,W. - Sihan, C. - Danya, Y. -Yi, Z.- Li, L.(2009), Delay Estimates of Mixed Traffic Flow at Signalized Intersections in China. Tsinghua Science and Technology, Vol. 14(2), 157-160. 